ISSN 1984-3755

Licenciado sob uma Licença Creative Commons

(c) $\underset{\mathrm{BY}}{\mathrm{B}(\mathrm{NC})}$

\title{
Percurso de um psiquiatra ${ }^{1}$
}

\author{
Percorso di uno psichiatra
}

Journey of a psychiatrist

\begin{abstract}
Angela Ales Bello
Professora de História da Filosofia Contemporânea na Universidade Lateranense de Roma, Itália, diretora do Centro Italiano de Pesquisas Fenomenológicas afiliado ao The World Phenomenology Institute - EUA, e-mail: aleca@flashnet.it
\end{abstract}

\section{Resumo}

0 artigo apresenta parte de uma conferência da autora num encontro de filósofos, psicólogos e psiquiatras que trataram do pensamento do renomado estudioso italiano Bruno Callieri - médico pioneiro na Itália na pesquisa multidisciplinar e na psicopatologia antropológica, e membro do Centro italiano de Pesquisas Fenomenológicas. Callieri, de fato, compreendeu que cada disciplina, se quer ser profundamente consciente dos seus fundamentos, deve retomar noções que superam o âmbito de uma pesquisa especialística. 0 autor superou o reducionismo que o positivismo comporta

1 Este artigo foi traduzido pelo prof. Dr. Márcio Luiz Fernandes. 
e se aventurou - já na sua juventude - no grande mar de uma pesquisa cujos confins estavam ainda por ser estabelecidos.

Palavras-chave: Psicopatologia antropológica. Psiquiatria. Descrição fenomenológica. Mundo da vida.

\section{Sintese}

L'articolo presenta parte di una relazione fatta dell'autrice nei incontri tra filosofi, psicologhi e psiquiatri elaborando il pensiero del famoso studioso italiano Bruno Callieri medico fra i primi in Italia nella ricerca moltidisciplinare e nella psicopatologia antropologica - membro del Centro italiano di ricerche fenomenologiche. Callieri, infatti, ha compreso che ogni disciplina, se vuole essere consapevole fino in fondo dei suoi fondamenti, deve risalire a nozioni che superano I'ambito di una ricerca specialistica. L'autore ha superato il riduttivismo che il positivismo comporta e si è avventurato - già nella sua giovinezza nel gran mare di una ricerca i cui confini erano da stabilire.

Parole chiave: Psicopatologia antropologica. Psichiatria. Descrizione fenomenologica. Mondo della vita.

\section{Abstract}

This paper is part of a conference of an author in a meeting of philosophers, psychologists and psychiatrists who discussed the renowned Italian studious' thoughts Bruno Carllieri - pioneer doctor in Italy in the multidisciplinary research and anthropological psychopathology and member of phenomenological research center. Callieri, as a matter of fact, understood that each subject, if considered working consciously in its assumptions, should reprise smattering that overcome the specialist style of research. The author overcame the reductionism that positivism includes and ventured - even in its youth - in the extremely large group of researches which the ends have not been established yet.

Keywords: Anthropological psychopathology. Psychiatric. Phenomenological description. Life-world. 


\section{Introdução}

O título deste artigo retoma, modificando-o levemente, aquele de um dos muitos livros de Bruno Callieri ao qual o livro Corpo esistenze mondi: per una psicopatologia antropologica (2007) está idealmente ligado. Trata-se de Percorsi di uno psichiatra ("Percursos de um psiquiatra", Edizioni Universitarie Romane, Roma, 1993), que aborda alguns dos temas aqui repropostos e aprofundados. A escolha deve-se ao fato de que o caminho de pesquisa do professor Callieri nos impressiona pela linearidade e, ao mesmo tempo, pela consequente argumentação que consente um procedimento contínuo e ininterrupto.

A amplitude de interesses do nosso psicopatologista não cessa de causar admiração. Sua atenção em relação a todos os fenômenos culturais, sociais e patológicos que caracterizam o nosso tempo é constante, incansável, e demonstra uma extraordinária vivacidade intelectual que não se contenta com o já conquistado. Algumas pessoas, tendo obtido os reconhecimentos, a admiração, a estima que Bruno Callieri mereceu, poderiam ficar satisfeitos e considerar que já concluíram com resultados absolutamente positivos a própria pesquisa. Ao contrário, o professor Callieri, com juvenil vivacidade, prossegue explorando movido pela curiosidade e encantado pelo novum que não lhe escapa.

Uma atitude como essa nos permite a leitura dos fenômenos que são pesquisados com renovado aprofundamento, levando em consideração também as contribuições dos jovens pesquisadores, em grande parte seus alunos, e também de estudiosos de outras disciplinas, sobretudo da filosofia. Bruno Callieri, de fato, compreendeu que cada disciplina, se quer ser profundamente consciente dos seus fundamentos, deve retomar noções que superam o âmbito de uma pesquisa especialística, chegando às raízes do saber. Por outro lado, ele está convencido também da importância da pesquisa especializada. Em particular, a tarefa do psicopatologista requer uma investigação antropológica que capte a complexidade do ser humano, e só uma antropologia filosófica pode fornecer instrumentos adequados.

Nesse sentido, mesmo sendo profundamente competente no âmbito da ciência médica como se configurou na idade positivista, ele superou 
o reducionismo que o positivismo comporta e se aventurou - já na sua juventude - no grande mar de uma pesquisa cujos confins estavam ainda por ser estabelecidos. É por essa razão que pretendo começar o meu percurso de leitura do livro Corpo esistenze mondi - per una psicopatologia antropologica a partir de um dado metodológico fundamental que serve para indicar o caminho de Callieri.

\section{Tertium datur}

Contrariando as regras da lógica aristotélica, Callieri afirma que no âmbito dos estudos sobre os distúrbios mentais é possível traçar uma terceira via entre as duas que caracterizaram e caracterizam ainda esse âmbito de pesquisa, dividido pelo debate mind-brain e combatido entre o totalitarismo das neurociências, versão atualizada do funcionalismo positivista e das correntes psicanalíticas, também estas filhas do positivismo. Callieri escreve: "Mas ao lado destes vastos desenvolvimentos dos estudos sobre a mente e sobre o cérebro, há o tertium, isto é, a dimensão antropoanalítica, cuja voz é bom que seja escutada tanto na Europa como além do Atlântico" (CALLIERI, 2007, p. 134).

Podemos nos perguntar para que serve ao psiquiatra a problemática e a análise existencial, proposta por filósofos que Callieri cita com grande competência: de Kierkegaard a Martin Buber, de Husserl a Farber, de Pfander a Geiger, até Edith Stein e os estudos por mim realizados, no âmbito da fenomenologia e da antropologia fenomenológica, em particular. De que modo tudo isso pode se tornar um tertium em relação à psiquiatria, uma ciência que se baseava sobre a proclamação de Griesinger, segundo a qual "as doenças mentais são doenças do cérebro"?

Tudo isso nos faz recordar que se trata da retomada de um tema antigo, discutido num momento e no âmbito privilegiado no qual se configura a cultura ocidental, ou seja, Atenas do século $\mathrm{V}$ com os fervorosos debates intelectuais que tinham como protagonistas os sofistas. Esses debates nos foram transmitidos por mérito daquele grande cronista que foi Platão. Naquela época e em tal sede já se discutia qual seria a relação entre os conhecimentos técnicos e as perguntas radicais que se relacionam com o tema do 
sentido da realidade, entre a especialização e a busca da verdade, palavra que hoje provoca medo. Mas o que buscam os seres humanos, senão aquilo que se mostra com evidência como válido e que nos dá o "sentido" do fenômeno?

Entre o fim do século XIX e os primeiros decênios do século XX, repropõe-se uma situação análoga, e isso porque, na segunda metade do século XIX, o processo de formação das ciências parecia ter chegado ao seu ápice, já preconizado por Comte na sua teoria positivista: ramificação, especialização do saber, baseado na experimentação e na verificação empírica. Bastam as "leis" de galileana memória, as "regras" de comportamento dos fenômenos para que eles se tornem claros - portanto verdadeiros. Para Comte a filosofia e a teologia são desviantes e ilusórias, fruto de uma mentalidade infantil e ainda incapaz de captar... o quê, afinal? Talvez, de novo, a verdade? Não se quer mais aceitar essa noção, que parece filosofia ou teologia - no entanto, o que se busca? Profunda contradição do positivismo! Escreve Husserl (2002, p. 55): "De fato, o positivista rejeita os conhecimentos essenciais só quando reflete 'filosoficamente', deixando-se enganar pelos sofismas dos filósofos empiristas, mas não quando, na atitude normal das ciências naturais, pensa e justifica as suas asserções como pesquisador científico da natureza. Neste último caso, de fato, deixa-se largamente guiar por evidências eidéticas".

Se isso é verdade para as ciências da natureza, é verdadeiro também para a psiquiatria, que se configurou de maneira naturalística, ainda que enfocando uma problemática que se refere ao ser humano em relação a seu ser no mundo, na sua orientação pessoal e nas suas relações com os outros. Callieri capta a insuficiência da visão puramente naturalística, exatamente porque o objeto da pesquisa é o ser humano e ao ser humano condiz uma pesquisa que consiga revelar seus aspectos essenciais. E qual é o aspecto essencial? Exatamente o sentido da sua existência, que se encontra no fundo de outras análises específicas que se referem às alterações da própria existência:

O fim da análise existencial - é necessário aqui recordá-lo falando do tertium datur - é o de adquirir uma rigorosa fundamentação da psicopatologia [...] baseando-a não sobre o ultramicroscópio ou sobre o bioquímico, sobre o pulsional ou sobre a transferência, mas simplesmente sobre 
o humano, sobre o dado imediato da relação interpessoal (CALLIERI, 2007, p. 136).

Trata-se de uma singularidade pessoal - e aqui Callieri recorda as lições de Mounier - aberta, isto é, aberta aos outros e ao mundo. O conceito de mit-sein, que por sua vez remete ao conceito de Heidegger e o de Lebenswelt, proposto por Husserl, servem para delinear essa abertura que não é somente horizontal, mas também vertical. Pode-se, portanto, falar aqui de uma transcendência.

Essa singularidade pode apresentar alterações de comportamento, distúrbios, mas como podem ser analisados, compreendidos, curados, se não se sabe quais são as linhas de fundo da existência humana? Os termos normal-anormal parecem uma alternativa falsa porque a normalidade enquanto tal não existe, então por que uma cura? Qual é a finalidade terapêutica? Mesmo se não se pretende reconstituir uma integridade que, de fato, não é realizável, a tendência é aproximar-se a um ideal de equilíbrio e sanidade que guia a pesquisa e a orienta. A força do ideal! E de onde provém? Tratar-se-ia de abordar filosoficamente a relação entre real e ideal, situação concreta e juízo sobre tal situação, sofrimento e tentativa fatigante de restabelecer o equilíbrio.

Por isso é necessário deixar-se orientar na pesquisa pelas linhas de fundo que emergem da análise sobre a existência.

A existência humana no mundo e com os outros elabora um projeto. Imediatamente somos conduzidos a perguntarmo-nos quais são as características desse projeto. Sente-se a exigência de alguém que seja psiqui-atra. Alguém se torna psiquiatra porque o projeto de mundo das pessoas, em alguns casos, adquire características peculiares, devemos dizer, francamente, tornam-se "distorcidas": "a presença, como projeto de mundo, em sua dimensão 'outra', isto é, psicótica, se encaixa completamente numa determinada imagem de mundo, numa particular carência ou distorção de 'projeto', pela qual se sente tomada e aniquilada" (CALLIERI, 2007, p. 138).

Assim Callieri descreve a razão profunda do seu ser psiquiatra, mas também a razão profunda do seu ser psicopatologista, isto é, um psiquiatra humanista, como bem o descreve Gilberto di Petta na introdução que 
faz ao livro de Callieri. Porque não basta indagar sobre processos bioquímicos e psicoanalíticos - isto se pode fazer e pode também ser útil -, mas é necessário aprofundar-se, como ensinou um dos grandes mestres da antropoanálise, Ludwig Binswanger, na "história interior da vida". Tratase, de fato, de passar do "como" - tarefa assumida pelas neurociências e também pela psicanálise, que ainda está inscrita em uma dimensão naturalística - para "o quê"; portanto, perguntar-se qual seja a "qualidade" daquela particular existência. E para fazê-lo é necessário orientar-se sobre o sentido da existência: o universal e o particular estão entrelaçados e se sustentam mutuamente.

\section{0 trabalho do psicopatologista}

A pesquisa do psicopatologista é, portanto, uma busca do "sentido". Ele rejeita "[...] de apegar-se ao significado como mero sinal ou sintoma, de excluir do campo teorético da psicopatologia o desafio da pessoa, a aposta densamente e arriscadamente existencial do seu propor-se [...]" (CALLIERI, 2007, p. 54).

A busca de sentido se volta para muitas direções: para a vivência do corpo; para a modalidade da presença no mundo; para a individuação do projeto existencial; para a autenticidade da vida.

A vivência do corpo é analisada seguindo as sugestões da escola fenomenológica - em particular, as contribuições de Merleau-Ponty. O corpo apresenta-se como um meio e um instrumento de relação com os outros. Delineia-se a dupla possibilidade de viver o encontro com o outro em plenitude ou, de modo alterado, como acontece nas psicoses delirantes. Tudo isso interfere nas possibilidades "de aproximação, de acesso, de verdadeiro, palpitante, vivo-contato, ainda que somente verbal" (CALLIERI, 2007, p. 72). É a antropofenomenologia que ajuda a captar o sentido da vivência do corpo nos seus aspectos positivos e, correlativamente, naqueles aspectos negativos que o tornam mera coisa, que o despersonalizam. A tarefa do psicopatologista é individuar as modalidades de despersonalização. E aqui se vê como é necessário um conhecimento aprofundado das patologias, que não são somente "classificadas", mas 
compreendidas no seu poder destrutivo das potencialidades que tornam impossível a realização de um projeto existencial pleno.

Particularmente importante é a análise que Callieri dedica à "Corporeidade do amor". Nesse texto ele examina o sutil e difícil equilíbrio entre sexo e amor, sobretudo com relação ao difuso costume social de nosso tempo, que tende a exaltar o papel da atividade sexual. As páginas que o autor dedica a esse assunto estão permeadas de um sutil e discreto lirismo, que não é uma fuga numa dimensão abstrata, asséptica e moralista. Ele sabe captar com grande realismo a presença dos aspectos impulsivos, sabe compreender porque a psicanálise tenha atribuído tanta importância ao Eros, porém não justifica a sua absolutização. A complexa estrutura do ser humano impede os fáceis reducionismos.

E é justamente a complexidade evidenciada, principalmente pelos filósofos da escola fenomenológica e por aqueles que analisaram a pessoa humana, que faz perceber a abertura espiritual (ainda que Callieri não use essa palavra, somos autorizados a propô-la, a partir das suas próprias argumentações) em direção ao outro. Amor é necessidade de troca, mas tal troca, para coenvolver a totalidade do ser humano, requer uma relação pessoal exclusiva: "Enquanto o exercício do sexo é possível com muitos [...] e é também possível no anonimato, o eu te amo é possível somente com um, e supõe sempre um chamado, o nome, aquele nome exclui os outros, qualquer outro" (CALLIERI, 2007, p. 82).

Essas indicações de fundo são utilizadas por Callieri para compreender as patologias daquele sentimento, ou melhor dizendo, daquela atitude existencial global que é positiva se ligada também a um projeto maduro, autêntico. Se isso não acontece, a abertura ao outro fica comprometida. Falta a troca e se cai na insatisfação e na instabilidade. Com muita acuidade Callieri descreve as patologias do casal, que vão da dissociação entre plano afetivo e plano sexual à ausência de afinidades profundas e à excessiva interdependência pessoal, vão da dependência em sentido único até ao ciúme.

A crise de casal é sinal de uma patologia que, porém, se distingue no seu grau de gravidade das verdadeiras e próprias patologias. Na melancolia assiste-se a uma diminuição da dimensão afetiva - já os indivíduos no estado maníaco sofrem a fragmentação dos sentimentos que impedem a 
comunhão de vida. O procedimento descritivo de Callieri é pontual, essencial porque escrito em poucas páginas e com poucas palavras, e reconstrói um vasto continente de perturbações que podem ser reduzidas fundamentalmente a dois comportamentos: a agressividade, que está no fundo de todas as condutas pseudoamorosas de base sadomasoquista, e a histeria, fonte das condutas egocêntricas, particularmente presentes no "teatro do mundo" do nosso tempo, segundo a definição do autor.

Detive-me sobre esse capítulo do livro do professor Callieri dedicado ao amor porque considero que deveria ser lido por todos e também por aqueles que não são especialistas na matéria. De fato, cada um pode encontrar o retrato de si mesmo e, se está em condições não tão patológicas, pode encontrar também a força, o estímulo para uma profícua autorreflexão. Não está afirmado de modo explícito, mas se entrevê - como pano de fundo - uma relação entre psicopatologia fenomenológica e ética.

Como se pode notar, a existência, que está no centro da pesquisa de Callieri nesse livro, emerge como um tema complexo. Sua especificidade se compreende de várias maneiras, cada uma das quais remete a outra, e é nesse contínuo processo que se esclarece o sentido da vida humana.

\section{0 mundo-da-vida}

A existência humana é uma existência "mundana”. Essa tese, sustentada por Heidegger, na realidade tem sua fonte nas análises de Husserl sobre a relação eu-mundo, mas sobretudo na sua concepção de mundo. O mundo não é o conjunto das coisas que estão fora, mas é aquilo que está dentro de nós, a modalidade com a qual cada um de nós vive a relação com as coisas e com os outros seres humanos.

Callieri (2007) exemplifica - de modo admirável - tudo isso na descrição de dois momentos da existência humana, ligados ao seu início e ao seu fim: o mundo da criança e o mundo do velho.

Descrição delicada, respeitosa e atenta é a do mundo da criança. As características essenciais que emergem são encontradas num lugar concreto, real: o próprio quarto. Nesse exame Callieri procede como um verdadeiro fenomenólogo, inspirando-se na epochè husserliana, distinguindo 
a nossa atitude cotidiana, banal, natural, que nos conduz a afirmar que o quarto está em desordem e a outra atitude que nos faz, conscientemente, depois de ter colocado entre parênteses a primeira, afirmar que o quarto está em desordem do ponto de vista da ordem que o adulto considera como tal. O quarto, porém, fala da vivência da criança no seu mundo. Então, devemos segui-lo, porque da análise que se delineia emerge também a fase de desenvolvimento em que se encontra a criança.

Cada brinquedo individualmente manifesta uma maior ou menor capacidade indicativa, sem dúvida ligada à nossa capacidade de decifrar amplamente a intenção mais ou menos expressa de comunicar (CALLIERI, 2007, p. 180).

O mundo objetual é, desse modo, um mundo eloquente, que remete às vivências de caráter corpóreo e psíquico. As experiências que a criança faz com relação ao conhecimento e manipulação dos objetos são compreensíveis por meio da gênese da relação sujeito-objeto, assim como foi descrito por Husserl nas suas Análises das sínteses passivas (HUSSERL, 1993). Callieri (2007, p. 181) acena ao "contínuo fluir hilético de energias" no constituir-se perceptivo do mundo. Husserl nos fez descobrir operações que precedem a percepção, por meio das quais somos afetados passivamente pelas coisas e reagimos a elas, distinguindo-nos progressivamente delas e constituindo, desse modo, uma relação entre o sujeito que conhece e o objeto conhecido.

Antes de chegar a essa consciente distinção devemos passar pela primeira fase hilética em que a criança, bem como os seres humanos nas épocas arcaicas da cultura, permanecem mais tempo, e se sentem "em casa”. É necessário, porém, indicar uma diferença fundamental entre as duas posições para não ceder a um fácil evolucionismo de caráter positivista. A diferença consiste no fato de que o momento noético, intencional de reconhecimento, no qual acontece a formação dos juízos, será completado pouco a pouco na criança, enquanto nas culturas arcaicas está presente, ainda que em formas conceituais que devem ser indagadas para serem compreendidas no seu valor particular. Pode-se recordar aqui uma afirmação de Husserl, segundo a qual os primitivos - assim ele ainda os chamava, aceitando a denominação proposta pela antropologia cultural 
do tempo - não estão privados da lógica, mas têm o seu procedimento lógico peculiar.

Tudo isso indica a complexidade da constituição humana - a sua estratificação mostra-se como uma verdadeira chave interpretativa em diversas situações.

Se nos detemos na análise da Lebenswelt do velho, nota-se que o objeto, já configurado e interlocutor real - mais ainda, privilegiado -, se torna extremamente interessante. Também nesse caso o objeto nos remete à presença total imediata do ser humano no mundo, mas no caso do velho há uma diminuição de cada possibilidade de buscar. "O objeto - escreve Callieri (2007, p. 182) - mais do que percebido, vem idealizado, mas sofre de uma idealização que em última análise é uma pura constrição para um lento fechamento de outras possibilidades".

Poder-se-ia arriscar dizer, à guisa de comentário, que se trata de uma espécie de esclerose da dimensão noética, que é a fonte da idealização. A idealização, instrumento importante e especificamente humano, não se encontra mais em contato com o momento hilético-experiencial, contato que torna dinâmico o conhecimento que, por sua vez, é também expectativa de novidade. O velho - mas felizmente não todos os velhos mostra não ser mais capaz de projetar. E é justamente por isso que Callieri faz referência ao processo temporal, estudado e colocado em evidência em primeiro lugar pelo próprio Husserl e por todos os fenomenólogos. Para elaborar um projeto, é necessário que esteja viva a dimensão do futuro presente na vitalidade da criança só potencialmente, porque o projeto requer o desenvolvimento do momento noético que ainda está latente. Também o velho tende a fechar-se no passado, pois o futuro não tem mais sentido. Estranha coincidência entre as duas situações, e por motivos opostos!

Esta análise a partir da normalidade consente a Callieri compreender mais profundamente as situações patológicas. O fóbico, o fóbico-obsessivo, o melancólico, o maníaco têm distúrbios que são compreensíveis somente sobre a base das faltas, das falências na constituição do seu mundo-da-vida. Cada vez as coisas assumem um peso extraordinário, como no caso do fóbico, ou se constituem como um antimundo hostil, como no caso do fóbico-obssesivo. Outras vezes, assumem um sentido 
puramente lúdico, mas sem projetualidade, como no caso do maníaco, ou fixam-se em um mundo sem sentido, no qual falta uma dimensão afetiva, como no caso do melancólico.

Trata-se - como já foi indicado também por Binswanger - de distúrbios espaçotemporais, base interior indispensável para a formação da correlação entre mundo interior e coisas que se manifestam a nós.

\section{0 mundo do sagrado}

A análise feita até aqui da existência, corpo e psique não seria completa se não se abordasse a questão do sagrado. Segundo Callieri (2007, p. 287), "o sagrado como fundamento pré-categorial do religioso sempre indicou a via para a abertura e interdições fundamentais à existência humana".

Seguindo as leituras mais atentas desse fenômeno, Callieri (2007, p. 287) compreende muito bem o valor e a presença perene daquilo que ele define como o elemento constitutivo "imaginário de um universo orientado, exigente, cheio de promessas e, sobretudo, significante", que permitiu ao ser humano sobreviver. O sagrado como fonte de cultura, sempre presente nas suas diferentes acepções tiradas da linguagem dos diversos povos, indica a abertura, a transcendência do ser humano em direção a algo que ultrapassa a si mesmo.

Como psiquiatra, Callieri atribui a origem do sagrado à imaginação criativa, mito poético e, portanto, muito diferente da mentalidade científica, mas não por isso menos válida. Ele concorda com Rudolf Otto, segundo o qual a categoria do sagrado é uma categoria humana fundamental, irredutível e primária.

Por meio de um rigoroso diálogo com os antropólogos culturais, Eliade, De Martino, Kalinowski, Lévi-Strauss, com os filósofos de orientação fenomenológica de Husserl a Schutz, de Merleau-Ponty a Ricoeur, de Tymieniecka a Ales Bello, com os psicanalistas - particularmente Jung e Szondi -, Callieri chega à conclusão de que o sagrado tem sua raiz potentemente na psique humana. Poderíamos observar - e muitos em nossa época fazem isso - que se está enraizado na psique humana. Poder-se-ia 
também desenraizar-se e talvez seria oportuno proceder ao seu desenraizamento (pense-se a Ludwig Feurbach).

$\mathrm{O}$ autor rejeita com a força da argumentação essa proposta que nasce da tentativa de dessacralização da época contemporânea. Não somente faz notar que o sagrado está presente em todas as culturas, mas, recolocando-o na sua raiz psíquica, não deduz daí seu valor ilusório, mas, ao contrário, declara entendê-lo não como "mero jogo de fantasia avulsa à realidade, mas como lugar profundo e polimórfico momento da existência, constitutivo para o homem e constituinte para o seu mundo, também na sua última exigência, tanto ontológica quanto erótica, que é aquela da fundação husserliana do Alter-Ego" (CALLIERI, 2007, p. 296).

Nesta última expressão, o uso das maiúsculas enfatiza que se trata de uma transcendência que coenvolve também os relacionamentos inter-humanos na sua autenticidade, como sustenta Emmanuel Levinas, constituindo a base da responsabilidade ética, mas dando-lhe uma ulterior especificação: aquela da antiga sabedoria bíblica. Pode-se notar que com Levinas chegamos a realizar a passagem do Sagrado ao Santo. E, desse modo, entramos na dimensão religiosa, na qual o espírito - termo, como já dissemos, nunca utilizado por Callieri, mas muito frequentemente evocado - e não só a psique, manifesta toda a sua força de abertura em direção aos outros e em direção ao Outro.

\section{Referências}

CALLIERI, B. Percorsi di uno psichiatra. Roma: Edizione Universitarie Romane, 1993.

CALLIERI, B. Corpo Esistenze Mondi: per uma psicopatologia antropológica. Roma: Edizione Universitarie Romane, 2007.

HUSSERL, E. Lezioni sulla sintesi passiva. Tr. it. di Vicenzo Costa. Milano: Guerini e Associati, 1993. 
HUSSERL, E. Idee per una fenomenologia pura e una filosofia fenomeno-

logica. Nuova edizione a cura di Vicenzo Costa, Introduzione di Elio Franzini. Torino: Einaudi, 2002.

Recebido: 30/01/2011

Received: 01/30/2011

Aprovado: 02/03/2011

Approved: 03/02/2011 